\title{
Epistemología y aforismos. Usos de la antropología contemporánea
}

\author{
Epistemology and aphorisms. Uses of contemporary anthropology
}

Rossana Cassigoli (rcassigoli@gmail.com) Centro de Estudios Latinoamericanos, Universidad Nacional Autónoma de México (Ciudad de México, México) ORCID: 0000-0002-9177-7098

\begin{abstract}
This paper identifies epistemological principles that would come to define the task of anthropological research. These principles are theoretical assumptions which would inform the practice of a discipline based on a method of qualitative observation, and on the systematic recording of the things observed with a markedly subjective tone. In this study, I offer a proposal on the ethical stance implicit in the acknowledgement and explicitation of the locus of research, which would in turn underpin the articulation of an explanatory discourse that is demonstrative in nature. A hypothetical researcher would be aware of the multi-dimensional and subjective representation of the phenomenon observed and shun immediatist or prescriptive interpretations. In the conceptual framework offered by Bourdieu, interpretation in this case would entail a modus operandi as a practical expression and "common sense" as a cultural manifestation. What is proposed here is a meditative observation that would result in the co-involvement of the anthropological subject in that which the anthropologist seeks to explain.
\end{abstract}

Key words: place of enunciation, historicity, poetry theory, qualitative observation, meditative observation.

\section{Resumen}

El presente artículo distingue principios epistemológicos que darían forma al oficio investigativo de la antropología. Se trata de presupuestos teóricos que encauzarían la práctica de una disciplina basada en un método de observación cualitativa, y en el registro sistemático de aquello observado bajo la forma de una huella subjetiva. En este trabajo se reflexiona sobre la postura ética implicada en el reconocimiento y explicitación de un locus investigativo, que sustentaría, a su vez, la articulación de un discurso aclaratorio con carácter demostrativo. Un hipotético investigador será consciente de la representación multidimensional y subjetiva del fenómeno que observa, manteniéndose a resguardo de la acción interpretativa inmediatista y prescriptiva. En el marco conceptual que nos provee Bourdieu, la interpretación entrañará, en este caso, un "modus operandi" como expresión práctica y un "sentido común" como manifestación cultural. Se propone aquí una observación meditativa, que derivaría en la coimplicación del sujeto antropológico en aquello que intenta explicar.

Palabras clave: lugar de enunciación, historicidad, teoría poética, observación cualitativa, observación meditativa. 


\section{Introducción}

Este escrito pretende distinguir principios epistemológicos que darían forma al particular oficio investigativo de la antropología. Tales principios entrañan presupuestos teóricos, que a su vez rigen la práctica de una disciplina basada en la observación cualitativa. Adicionalmente, esta práctica disciplinaria implica un registro sistemático de 'hechos' que, al elaborarse de acuerdo con la particular forma de trabajo de cada investigador, constituiría una huella o "firma subjetal". El investigador demarcará los criterios e hipótesis que ordenan la observación, procederá a inscribir sus representaciones y reflexiones, y subsiguientemente incursionará, si acaso, en el orden de la interpretación siempre abierta, ambigua, controvertible, especulativa e inacabada.

Tal hipotético investigador será consciente de la representación multidimensional y subjetiva del fenómeno que observa, manteniéndose a resguardo de la acción interpretativa inmediatista y con frecuencia prescriptiva. Para ello debería comprometerse a explicitar el régimen ético de su interpretación. Entendiendo por tal régimen el ideario valorativo que subyace en el intelecto del investigador y que anima las preguntas que este suscita. Se trata de una ética que actuará también en el sentido de formar un ethos investigativo, es decir, un sistema conceptual, un horizonte interpretativo y hasta una cosmovisión. Tal ethos alude, así mismo al conjunto de elementos de un habitus -acoplamiento entre las practicas humanas y un hábitat. Dicho conjunto devendrá parte priomordial del mundo significante $\mathrm{y}$, al condicionar los procesos mentales del sujeto, definirá el carácter de su racionalidad práctica. En este contexto, la interpretación será resultado de un modus operandi por parte del investigador. Expresión práctica, a su vez, de un sentido común como manifestación cultural.

La disciplina antropológica daría lugar a un observar meditativo, "otro subsuelo" en la expresión de Michel de Certeau. Es decir, un tipo de observación que conduciría a la captación de lo inaparente, de lo que subyace tras el primer plano visual. Un nuevo "sistema de posibilidad reorganizador del universo flotante de las palabras y los conceptos [irrumpiría en la escena investigativa]. Sistema que implicará, por medio de sobrevivencias e invenciones, un 'campo epistemológico' [...]: cada episteme está hecha de lo heterogéneo" (de Certeau 1995a:11). El texto se refiere a la existencia de una suerte de "humus memorístico' o vestigio de lo colectivo, formado por fragmentos de unas costumbres que son producto de la capacidad creativa humana y que han perdurado. "Subsuelo", en la expresión de Humberto Giannini, que remite a un estado sedimentario de la experiencia común, como origen y tempo común. Idea que tomó su impulso del pensamiento de Enrico Castelli: "concretamente, en la revalorización gnoseológica y ética de la experiencia común como "criterio absoluto de verdad»" (Giannini 1987:18).

Este trabajo se propone distinguir los presupuestos teóricos y/o principios epistemológicos que darían forma al referido particular oficio investigativo de la antropología. Metodológicamente, se busca asimismo explorar las formas bajo las cuales la condición "situada" de un investigador fortuito determinará la creación de teoría y/o reproducción de saberes disciplinarios. Condición situada que se refiere a la determinante influencia que ejercen las vicisitudes del contexto temporal, histórico, simbólico y personal del sujeto que enuncia. En este caso, del propio investigador. La construcción de su enunciado estará determinada por la ya referida "huella subjetal", en la expresión de Henri Meschonnic. Empero, puesto que esta impronta del sujeto sería a todas luces inevitable, es preciso que el investigador debe apegarse a estrictos lineamientos de objetividad analítica.

Por último, este trabajo intenta reflexionar sobre la postura ética que implicaría la explicitación de un lugar de enunciación, locus investigativo o "lugar y comienzo" (de Certeau 1995b:20). Esta suerte de lugar 
simbólico, desde donde el investigador despliega su proclama, alude a un conjunto de condiciones de muy diversa índole: abarca desde la condición particular, psíquica y emocional por la que atraviesa un investigador en el momento determinado de elaborar su discurso, hasta el tiempo histórico en el que lo hace. Incluye, por último, el bagaje teórico, ideológico o ético que sustentará la articulación de su discurso demostrativo: "el historiador debe poner de manifiesto su propio lugar" (de Certeau 1995b: 20).

La enunciación se entenderá, de la mano de Emile Benveniste, como el "acto individual de su producción y ejecución en la lengua" (Benveniste 1971:83), mediante el cual un sujeto se apropia de ésta para transformarla en discurso. Constituye un acontecimiento nominativo, según Benveniste; algo que no estaba allí antes de ser hablado. Para Michel de Certeau, la enunciación tiene que ver con el estilo; la elocutio de la antigua retórica. El estilo prefigura las marcas de su lugar de producción; remite "a una teoría de los afectos y su representación" (de Certeau 1995b:111). Para Michel de Certeau el discurso de Sigmund Freud es un claro ejemplo de la enunciación entendida de esta forma: "no se sustrae a los mecanismos que descubre en sus objetos [...] como si ocupara la posición privilegiada de una «observación». Esclarece un funcionamiento en el cual él mismo está sometido" (de Certeau 1995b:112).

Para de Certeau, el acto de "tomar la palabra" deviene "crítica teórica de la sociedad" y crítica filosófica a la "ley del lugar" (de Certeau 1995a:16). Una ley que alude no solo al ordenamiento jurídico de la polis, sino también a la acción de "decir" ahí realizada como principio constitutivo de lo social; la expresión verbal como vía de acercamiento al semejante. Ello entraña una responsabilidad práctica; podría devenir en una forma de hacer política entendida como "proyecto de dilucidación común" (de Certeau 1995a:9). La responsabilidad práctica se traducirá en la explicitación deliberada del sitio particular del hablante -mediante un discurso 'articulado' o expresión oral libre-, "en lugar de enmascararlo bajo un discurso supuestamente capaz de agrupar a los otros" (de Certeau 1995a:20). Es decir, el investigador deberá dejar muy en claro que su discurso, originado en tal sitio particular, es sustentado primordialmente por sus posturas personales e individuales; no pretende erigirse en intérprete de un sentir colectivo. Esta afirmación o confesión de un sitio particular parece coincidir con el sentido de volver intencional y reflexiva la "acción comunicativa", en la dirección de una reflexión de la vida cotidiana. Una acción que debe apoyarse en la "moralidad" que establece un código de interacción comunicativa entre semejantes: "comunicarse con otro ser humano mediante alguna referencia al mundo" (Giannini 2011:167).

Debido a lo expuesto, podríamos afirmar que, metodológica y transversalmente, un primer objetivo de este escrito sería el enfatizar la importancia de la explicitación o "develación" de los referidos 'locus' enunciativos. Ellos guiarían implícitamente los pasos de un trayecto interpretativo que aspira a presentar lo "real" -una representación verbal u oralizada de lo que se concibe como realidad. Tal locus, no obstante, podrían tener la apariencia de lapsus, cuando el investigador emite señales inconscientes o involuntarias que lo revelen. Un procedimiento tácito tomaría la representación de este "real". Lo hará sin las reservas y precauciones que Michel de Certeau enfatizó, al dirigir su crítica al discurso que equipara lo "real" a la "ley", develando así el funcionamiento de la ficción en el discurso historiador. Al luchar contra la ficción, la historiografía occidental produce una distancia con el decir y el creer comunes: "la guerra intestina entre la historia y las historias es muy remota" (de Certeau 1995b:51).

En resumidas cuentas, la historiografía se labra un terreno propio que excluye lo erróneo ficcional, confinando esto último al ámbito de lo 'irreal'. En el nivel de las interpretaciones, tal discurso se autoriza mediante el mecanismo de hablar en nombre de lo real. El mismo mecanismo antiguo que argumentaba en contra de los "falsos dioses" pervive, según de Certeau, en la historiografía contemporánea. En oposición a la pretensión historiográfica -de este modo culmina el autor su argumento-, la ficción, bajo sus 
modalidades míticas, literarias, científicas o metafóricas, es un discurso que "informa de lo real sin pretender representarlo ni acreditarse en él" (de Certeau 1995b:54). Los espectros cognitivos -de suyo ficcionales- se enfrentarán a una historiografía que "se funda siempre en la ambición de decir lo real, y, por lo tanto, en la imposibilidad de hacer su duelo de lo real" (de Certeau 1995b:54). Esto quiere decir que el volumen de energía y atención que el investigador ha volcado en el estricto relato de lo real le ha impedido darse tiempo para elaborarlo reflexivamente.

Como perspectiva complementaria, que ampliaría el examen de la construcción de lo "real" en la escritura histórica, es sugerente recordar la reflexión propuesta por Alain Badiou en su libro El siglo. En el fructífero apartado "Cuestiones de método", observa que la "obsesión por lo real” (Badiou 2005:13) -'cuantitativista' en este caso-, deviene rasgo paradigmático y distintivo del siglo XX. La opinión de autor revela, entonces, que el siglo XX encuentra su "real" en el exceso aplastante de cifras que representan el crimen y la dimensión industrial de la muerte.

El segundo objetivo trasversal de este trabajo es dar cuenta del fenómeno que Giannini conceptualizó como implicación y "complicación" de un sujeto pedagógico, o epistemológico, en lo que intenta explicar. Según Giannini, cuando el movimiento reflexivo "se vuelve, ahora sí, reflexión en el sentido psíquico, espiritual del término; cuando el pensador se encuentra, por así decirlo, entre 'la reflexión' espaciotemporal y la reflexión psíquica, entonces, nos parece, puede decirse que se encuentra implicado y complicado en aquello que explica; entonces, se encuentra, lo más humanamente posible, en el centro del drama humano" (Giannini 1987:12). De esta fuente tomo la idea que se refiere ciertamente a la condición del filósofo, pero compromete también al sujeto común cuando emprende el examen de la conciencia propia. En el momento que logra descubrir en ella, como revelación apaciguadora, una resistencia inmanente, una vía de escape al destino infalible de ser un "sujeto frágil", que desconoce el proceso en el que está inmerso y, en consecuencia, el lugar que ocupa en él. Un sujeto autónomo, por contra, sería capaz de vislumbrar la vicisitud particular que experimenta, percibir las señales del contexto en el que ella se produce, y percibir aproximativamente cuál es su propia ubicación en éste. La conciencia clara de tal proceso incrementará las posibilidades de afrontar la dimensión del brete, lidiar con él y remontarlo. Una vez superada esta etapa, será entonces posible asumir la "complicada" posición que entraña la acción del "decir": pronunciarse sobre la particular vicisitud experimentada y modular un discurso práctico sobre ella.

La dilucidación de la noción de praxis constituirá el tercer objetivo metodológico de este trabajo, derivado de los precedentes. El vínculo genealógico existente entre la noción moderna de "producción" y los conceptos clásicos de "praxis" y "poiesis", que Aristóteles expuso en Ética a Nicómaco, llevó a Hannah Arendt a distinguir entre poiesis -actividad de "producción"- y praxis -actividad de "acción". Una diferencia que surge claramente expuesta en el célebre ensayo de Julia Kristeva sobre Arendt: "La reificación y el utilitarismo a los cuales sucumbe la condición humana están ya en germen en la poiesis, comprendida de este modo. En cambio, en el seno de la polis como 'espacio de aparición' o 'espacio público' se desarrolla la acción (praxis); que no es una fabricación, sino un 'posibilidad suprema del ser humano'" (Kristeva 2006:88).

La praxis, conceptualizada por Aristóteles como energeia o 'actualización', comprende actividades que no persiguen un fin (ateleis) ni dejan obra (par'autás erga), sino que se agotan en la acción misma de su significación. Objetando el "activismo vitalista" y el "utilitarismo antropocéntrico" del homo faber (hombre que fabrica cosas), Hannah Arendt vindicó la praxis aristotélica: "La vida, en su sentido no biológico, el período de tiempo que tiene todo hombre entre nacimiento y muerte, se manifiesta en la acción y el 
discurso" (Arendt 2005:195). El discurso y la acción serían las expresiones que revelan esta única cualidad de "ser distinto"; los modos en que los seres humanos se presentan unos a otros, no como objetos, "sino qua hombres" (Arendt 2005:206). La condición humana resulta aquí ontológicamente rescatada para un ámbito y un valor anti-instrumental de la vida, colmado de significación.

\section{La intencionalidad moral de la acción y el problema ético del "lugar de enunciación"}

Tomo como punto de partida la importancia que adquiere, en la obra filosófica de Humberto Giannini, el referido principio de la "intencionalidad moral de la acción", particularmente de la "acción comunicativa" (Giannini 2011:169). Mediante la explicitación -no forzosamente literal- del lugar de enunciación del sujeto investigativo, y considerando el principio de intencionalidad de la acción, la antropología sentaría las primeras bases de su epistemología y las herramientas de crítica a su propia praxis.

La noción "lugar de enunciación", o locus, aparece etimológicamente emparentada con el vocablo voz; imagen lingüística fonética de la emoción experiencial. Así mismo, se presentaría como dicción subjetivada, emergente de un acontecimiento que, según Badiou, alude a un "fragmento local de un procedimiento de verdad" (Badiou 2005:16). Por tal proceso, el filósofo entiende la decantación de la verdad en una experiencia particular. Es decir, una verdad primordial que atañe a un solo individuo o a una comunidad inadvertida. Tal acontecimiento, complementaría Michel de Certeau, resultaría indisociable de las opciones a las que da lugar. En contraste con esta visión del acontecer y el acontecimiento, es frecuente observar una adhesión emocional y acrítica a lemas constituyentes de un orden identitario que ignora aquellos acontecimientos "locales de la verdad". Cuando la identidad fija "detiene el gesto de pensar" rinde "homenaje a un orden". Pensar, por el contrario, escribió de Certeau, "es interrogar ese orden" (de Certeau 1995a:40).

El concepto de "lugar de enunciación", entonces, no aludiría únicamente al reconocimiento de una voz fundacional que instituye lo "propio" en el despliegue discursivo. Representaría, también, la nitidez de la configuración de hechos que sustentan una postura, querella, o valor testimonial demostrativo. Además, el concepto de "lugar de enunciación" explicita el compromiso con una palabra que pasa por los hechos. Ello equivaldría a la acción voluntaria de transparentar las condiciones y vicisitudes particulares que harían inteligible el sentido de la acción del pensamiento.

El significado de decir algo entrañaría un problema antropológico, en virtud de su carácter de producción simbólica y de sentido. Así mismo, involucra un enfoque epistemológico, en tanto sugiere para el análisis la existencia hipotética de un lugar fundacional, conceptual, lingüístico, disciplinario, identitario. Que es la plataforma sobre la cual el investigador despliega su teoría y demostración. En tal lugar fundacional pueden oírse las reminiscencias de una suerte de sentido original, abolido, a la zaga, por las sucesivas interpretaciones y excesos lingüísticos. "Abolido por todo lenguaje ulterior" (de Certeau 1996:16). Una demolición renovadora, que a su vez llevaría a la asunción congruente de un lugar de enunciación. Lugar desde el cual, como se ha dicho, se formula el discurso enfrentado a una visión ficticia, supuestamente compartida y consensual. Visión que provendría de la referida adhesión emocional acrítica a lemas constituyentes de un orden identitario.

La emergencia del enunciado no excluye la participación corporal y emocional del sujeto que enuncia, tanto en la acción comunicativa y estrategia discursiva, como en las formas y giros de su expresión oral. Sobre ello de Certeau cifra: "La fuerza anónima de un dolor, de una cólera o de una risa de la muchedumbre cautiva, inquieta, invade algunas veces y destruye el edificio del saber" (de Certeau 
1995b:48). Participación emocional del cuerpo vivamente ilustrada en la poética de Paul Celan, filósofo que según Jacques Derrida le hizo una "marca corporal" a la lengua alemana; "lengua herida". Se refería al alemán de giros regionales confiscado por los nazis en los campos de exterminio. La vida y la obra de Celan -el asesinato de sus padres en cámaras de gas, en 1942 y su propio suicidio en París, en 1970- han resultado ser referentes distintivos de una noción moderna de "poética". Entendida ésta como el trabajo del sujeto y la ética en el lenguaje. De acuerdo con Derrida, un sujeto poético puede infligir una marca en la lengua cuando, por ejemplo, la sustrae de su entorno totalitario, la humaniza, la recupera para la poesía. Celan hizo de ello un paradigma. La lengua alemana había muerto, según la máxima de Steiner citada por Glantz.

Existe, desde luego, una variedad de hitos literarios, fuentes históricas y entreveros teóricos que darían cuenta de la participación emocional del sujeto, mediada por una corporeidad, en la articulación de la lengua cotidiana. Una breve exploración contribuiría a consignar puntos de ruptura entre el hablar espontáneo, marrullero, escamotador, eufemístico y creativo del hablante, y la norma lingüística socialmente establecida. Una etnografía del habla cotidiana revelaría las "mil prácticas" escritas y orales del lenguaje, en todas sus modalidades, desde el discurso volitivo hasta la expresión inarticulada o los "Ilamados desorbitados de sentido" (de Certeau 1993:226). El relato oral, según de Certeau, se "practica"; es un hacer cuyo primer implicado es el cuerpo. Particularmente el relato oral entraña prácticas que reproducen un arte sin edad, transferido desde las primeras formaciones humanas heterogéneas, que dieron forma a repertorios colectivos reconocibles en los modos de utilizar el lenguaje. La escritura, por contra, separa el significante del cuerpo donde se produce el acto lingüístico; se abstrae de la "presencia" (de Certeau 1993:227).

\section{Función poética del objeto antropológico}

En la búsqueda de una definición de la función poética del objeto antropológico, se parte aquí de un primer antecedente: la afirmación de Claude Lévi-Strauss que sostiene que el modo del conocimiento humano es propiamente la aprehensión poética de su objeto (Lévi-Strauss 1971:9). Recordemos que se utiliza la noción de poética cuando aludimos a la posibilidad de transformación práctica del lenguaje en la vida e interacción cotidianas. Presencia, resistencia y trabajo creativo de un sujeto en el sistema de la lengua. La etnología "pierde pie", cifró Levi-Strauss, "cuando abandona el rigor poético por la exactitud" (Lévi-Strauss 1971:10). Es decir, cuando zanja la cuestión con interpretaciones inmediatistas o apresuradas de los hechos observados, sacrificando la visión poética que mira hacia una auténtica e infinita multiplicidad. El etnólogo capaz de "aprehender poéticamente su objeto" se prefiguraría, en contraste, como "ese hombre de ciencia que utiliza una poética para conocer [...] se va a tierras lejanas [...] de alguna manera elige este lugar, y aplicará métodos de conocimiento a algo que, hasta cierto punto, equivale a su poesía personal" (Lévi-Strauss 1971:16).

La fértil literatura destinada a descifrar una "poética" nos sorprende con la súbita revelación que experimenta un sujeto memorístico. Ella surge tras una incursión en el mundo, con un lenguaje que es propiamente acción. El referido sujeto responde, según Badiou, a la voluntad de "devenir" en cuanto tal. La acción de tal hipotético sujeto memorístico, interpretada desde la teoría poética decerteana y derridiana, daría cuenta de la irrupción de valores de resistencia, que emergen por la vía de una intencionalidad. Esta adoptaría un sesgo tenaz frente a los condicionamientos esclerotizados, derivados del uso automático y convencional de una lengua recibida y prescrita. Se trataría, entonces, de descubrir "en una manera de expresar una manera de tratar el lenguaje recibido" (de Certeau 1996:XLIII). 
Se suscribe aquí la propuesta de una poética deconstructiva del uso cotidiano del lenguaje. "Desmontaje de la lengua"; expresión de Ana Amado que se refiere a la deconstrucción del lenguaje por parte del sujeto. Tal concepto pareciera postular la desacralización del uso automático del lenguaje recibido. Dicho "desmontaje" se produciría al suspenderse la "disponibilidad" familiar del lenguaje; complejizarlo a tal grado que se haga necesario emprender una búsqueda precisa para llegar a él. Por su parte, Nicolás Casullo (Modernidad y Cultura Crítica) proclamó que, para ejercer la verdadera crítica que la ciencia del lenguaje emprende, será preciso franquear la barrera, interrumpir el curso de tal familiaridad y volver ese lenguaje "extranjero a nosotros mismos".

Idea que sugiere la búsqueda, por parte de un sujeto, de una manera de hacer equivalente a la del arte. En el contexto de este proceder, el sujeto experimentará libremente con la forma, a fin de encontrar al lenguaje como expresión de lo propio. El enigmático arte, ciertamente, interrumpe la convención que establecería las reglas de interpretación de un objeto. Según Nicolás Casullo, el arte es la única forma de significar una particularidad, es decir, de interpretar un objeto.

La noción decerteana de "prácticas ordinarias" constitutiría un segundo antecedente en esta indagación en torno a la función poética del objeto antropológico. Tal resulta noción útil para sustentar la declaración del principio que coloca a la antropología - ciencia humana que tiene entre sus temas fundamentales el estudio del lenguaje- en el umbral epistemológico de una teoría poética. Esta última estaría vinculada, entre otras fuentes, a la idea del "arte de pensar" en la obra de Immanuel Kant (de Certeau 1996:83). La indagación kantiana, según de Certeau, avanzó hacia la "crítica del juicio colocado en un acto ético y poético" (de Certeau 1996:84). Es decir, hacia el análisis del juicio valorativo, desde la perspectiva de una ética que incide directamente en el lenguaje.

lluminado por el hallazgo kantiano, de Certeau afrontó el examen de este "arte genuino y práctico descartado de los modus operandi científicos" (de Certeau 1996:82). Los ejemplos kantianos que captaron la atención de de Certeau atañen a un "conocimiento práctico que desborda el conocimiento y tiene forma estética" (de Certeau 1996:83). El conocimiento práctico se acercaría a la creación y el arte por su capacidad de reutilizar los objetos construidos para otros fines (de Certeau 1996:84). Se tratar de una "ciencia primera", descrita por Lévi-Strauss en la figura del bricolage. Expresión intraducible esta última, que se refiere justamente a la dimensión práctica del genio humano (Levi-Strauss 1964:35). Una "extrañeza de lo cotidiano" emergería en tal práctica, por obra de una "inteligencia del sujeto" (de Certeau 1996:82); interrupción de lo previsible y la rutina; ocurrencia, acierto y elevación del espíritu por obra del acto hábil y creador. La concepción del "hacer" en la obra de Michel de Certeau, resulta inherente a un "arte" y a un "estilo"; "dos nociones igualmente propias de la cultura jesuítica del Renacimiento" (Giard 1996:xxiv). Ambas nociones, explicó su prologuista Giard, le valieron a de Certeau la posibilidad de entender las prácticas culturales como un "estilo de resistencia moral" (Giard 1996:xxi).

Un complemento a los antecedentes se refiere a la identificación de la antropología -como disciplina específica, no solo como un general "modo de conocimiento humano"- con la "aprehensión poética del objeto". Es pertinente citar la diferencia ontológica que Henri Meschonnic estableció entre la poesía y el poema, análoga a aquella que Michel de Certeau vislumbró entre el poema y/o la institución. Meschonnic sostuvo que la implicación recíproca de los problemas de la sociedad, la literatura y el lenguaje configuran una poética; vale decir la "trama", el "lazo", la relación de la ética, la política, el poema y la historia (Meschonnic 2007:11). En tal perspectiva, la poética encarna una "energía crítica" en el proceso de búsqueda epistemológica. En virtud de ello constituye, además de una epistemología propiamente, una praxis. 
Meschonnic nos hizo ver que la actividad poética tiene que ver con "trabajar en darse cuenta" del dominio del signo. De esto se entiende la necesidad relevante de captar el cómo un "signo", o lo "sígnico", consiguen monopolizar el lenguaje, y las formas, tonos e intenciones de su práctica cotidiana. Sus "encarnamientos" en los usos particulares de los hablantes contribuyen a propagar la ficción de su poder. Resulta evidente que tal monopolización, o jerarquización del "sentido", se vuelve posible debido a la exclusión de "otros" sentidos; testimonios molestos, omisiones "involuntarias", etc. La poética de Meschonnic trabaja en reconocer la historicidad propia del discurso; los presupuestos y procedimientos implícitos o explícitos- de su fabricación. Si la poética es "el trabajo del poema", de "vivir el poema", entonces, concluye el autor, la poética es ella misma una antropología, una ética y una política. El poema surge, para Meschonnic, cuando un cambio en el lenguaje provoca un cambio en la forma de vida. En tal sentido, la poética afianza su nexo con lo político, en la medida de su compromiso con una promesa; una utopía inherente a lo humano.

Pensar el ritmo, argumentó Meschonnic, equivale a articular el cuerpo en el lenguaje. El "continuo" del ritmo, la particular frecuencia rítmica del hablante, sería lo que no se piensa (Meschonnic 2007:31). Tal metáfora revelará el hecho, en Meschonnic, de que la poesía constituye la representación del signo, en oposición al poema que, en adición a lo señalado en el párrafo anterior, constituye la verdadera "escucha" del lenguaje. Es en el ritmo del lenguaje, y no en su literalidad sígnica, donde radicaría la gramática experiencial, por así decirlo, de la lengua.

La captación del "ritmo continuo" de la lengua, como entiendo la propuesta de Meschonnic, conduciría entre otras prácticas a observar el fenómeno de la expresión en el ejercicio de la interacción lingüística. Asimismo, conduciría a practicar tal expresión en "carne propia" y, particularmente, a volver intencionada su escucha. Esta reflexión de la poética busca comprender la cuestión de la conciencia; ella impulsa no solo la captación del sentido intersubjetivo de las cosas cognoscibles, sino la trascendencia de este puro 'sentido' interpretado. Se trataría de una 'afinación' del oído que consigue escuchar el "ritmo" del "continuo" (Meschonnic 2007:54), cuyo barullo e inflexiones darían cuenta del verdadero significado de la comunicación humana.

Como lo imagina el antropólogo Michel de Certeau, la escucha tomará la forma de "citas de voces" (de Certeau 1993:23), "aproximaciones sucesivas", "palabras danzantes", "llamadas desorbitadas de sentido" (de Certeau 1993:226). Todo lo cual ostenta, de acuerdo con nuestro autor, una "pertinencia epistemológica" (de Certeau 1993:205). Por su parte, en la obra de Michel de Certeau, siguiendo a Mallarmé, el 'poema' surge como "un gesto a la vez estético y ético" que no se funda en el hecho, sino que "transgrede la convención social que quiere que lo real sea la ley. Le opone solamente su propia nada, atópica, revolucionaria, 'poética'” (de Certeau 1993:232). Según este principio, la verdadera revolución epistemológica y la legítima esencia del lenguaje se revelarían en el poema. Y esto es primordial: el poema aparecería, parafraseando el texto de Meschonnic, cuando la transformación de la vida se manifiesta en la transformación de la palabra y la transformación de la palabra se manifiesta en la transformación de la vida. En ello radica el primer carácter de la auténtica crítica.

En el Manifiesto por la filosofía de Alain Badiou podemos encontrar el cuarto antecedente de nuestra investigación. "La edad de los poetas" -uno de sus cuatro acápites- constituye un importante aporte a la reflexión sobre el principio epistemológico que enlaza la antropología con la teoría y práctica poética. En tal ensayo, Badiou distingue a los poetas cuya obra es reconocible como una obra de pensamiento. Obra de pensamiento en cuyo seno la poesía -entendida ésta en sus dos sentidos, como arte de creación lírica y como construcción creativa del lenguaje formal, discursivo- adviene como "el lugar mismo donde la 
filosofía flaquea" (Badiou 1990:49). La línea fundamental seguida por Badiou sugeriría una "destitución de la categoría de objeto y de la objetividad como formas necesarias de la presentación" (Badiou 1990:52). Aquí Badiou entiende por "presentación" el arreglo de la sintaxis que distribuye los elementos del lenguaje dentro, por así decirlo, del escenario del habla. Lo que intenta Badiou, en sus palabras, es abrir un acceso al ser ahí donde el ser no puede ampararse en la categoría presentativa del objeto.

La poesía nacería a partir de ese momento "esencialmente desobjetivante". Empero, según Badiou, esto no significa que el sentido sea cedido al sujeto, a lo subjetivo. El vínculo objeto/sujeto, explica, es constitutivo del saber, del conocimiento. Precisamente, "el acceso al ser" que la poesía busca no pertenece al orden del conocimiento. El poema se da, escribe Badiou, "cuando su autor como sujeto se ha ausentado" (Badiou 1990:52). La verdad del poema, entonces, adviene en la medida en que "lo que enuncia no testimonia ni de objetividad ni de subjetividad". La poesía ha destituido el cuadro objetivante sujeto/objeto: "Frente a la ley de la verdad que agujerea e inutiliza todo conocimiento, la desorientación poética supone la existencia de una experiencia sustraída simultáneamente a la objetividad y a la subjetividad" (Badiou 1990:53). La "desorientación poética" alude a la posibilidad de dejarse obnubilar por una concepción "dualista" que reduce la existencia al objeto como la abstracción de lo 'externo' y al sujeto como verdad absoluta de una interioridad particular. El sujeto de Badiou resulta invalidado, sea por "ausentamiento" o por "pluralización"; la verdad, según el autor, está sustraída a toda denominación exacta. Es decir, tampoco el sujeto tendría el privilegio de 'apoderarse' del poema, en tanto sujeto único que habla de sí o desde sí. Este sujeto se ausentaría del poema -ejercicio de deconstrucción epistemológica-, o se disolvería en un sentido de pluralidad como ley inherente a la condición humana.

\section{La noción de historicidad}

El concepto de historicidad resulta indisociable de la crítica a la "operación historiográfica" decerteana y, en general, de la crítica a todo el proceso de la escritura histórica. Tal concepto daría lugar a una epistemología fundamentada en la develación de los presupuestos y operaciones disciplinarias, ideológicas e interpretativas que producen el conocimiento histórico teórico. Tal como lo hizo visible de Certeau, la "operación historiográfica" alude, a mi parecer, a un proceso de producción de la historia como texto, narración y sentido. Este sentido de la historia se volvería posible solo en aras del "rechazo" de un conjunto plural de otros 'sentidos'. El investigador se ve "tragado" por una convicción caníbal; por un lado, no busca ponerse en jaque a sí mismo, en referencia a su conciencia voluntaria y a su postura ética, y por otro lado no osaría reflexionar los procedimientos conceptuales con los que piensa. El referido "rechazo" aparecería bajo la forma de una "negación" o "exceso"; "resistencia", "supervivencia" o "retardo" que trastorna "la hermosa ordenación de un 'progreso' o un sistema de interpretación" (de Certeau 1993:18).

Abordemos ahora la cuestión de la explicitación de las operaciones historiográficas. Ella exigirá seguir los pasos de un razonamiento que apela a la transparente comprensión de las motivaciones cognitivas originarias de cada particular operación. Tal explicitación constituye un problema relativo al antes referido 'locus de enunciación'. Según de Certeau, el análisis científico contemporáneo intenta reconstruir el "objeto" partiendo de "simulacros y argumentos"; es decir, se vale de modelos de lenguaje que propician la perpetuación de usos comunicativos. Éstos, a su vez, alimentan un modo de interactuar lingüístico. La antes referida noción decerteana de historicidad, en contraste, cuestionaría "la epistemología que gobierna en silencio el oficio del historiador" (Giard 1996:xiv). La historia sería lo que "toma el lugar' de tales acontecimientos" (de Certeau 1995b:113). De estos últimos solo permanecería un "desperdicio excluido de lo real", depositado en el proceso de la escritura. 
La referida historicidad dotaría de significado a la intervención de los sujetos en los sistemas de representaciones; escudriñaría lo esencial que se pone en juego "en la existencia de los sujetos que son los actores y autores de sus prácticas" (de Certeau 1996:25). Por último, se traduciría en la "capacidad de un grupo para transformarse a sí mismo; la manera en que una colectividad humana es un sujeto de su historia y no solo un producto de sus presiones" (de Certeau 1995a:211). Se observará, en el uso y práctica cotidiana de la lengua -desde un enfoque culturalista o naturalista-, su forma a veces esclerotizada, anclada a la costumbre. En tal uso predominan facetas nominativas-afirmativas, utilizadas en el ejercicio de su herramienta oral libre. Este uso se manifiesta en una trayectoria de trazos esquivos cuya racionalidad se ignora y cuyo procedimiento de elaboración teórica ("operación historiográfica"), si lo hubiera, permanece ciegamente implícito o veladamente oculto. De ser así, prevalecería un régimen ideológico del lenguaje. En tanto la investigación en ciencias humanas no explicite sus presupuestos, una "epistemología ciega", parafraseando a de Certeau, gobernará el oficio del antropólogo empírico, del historiador de la cultura, del filósofo de la práctica. Aunque parezca una perogrullada, la articulación conceptual y la observación de la propia praxis deberían preceder, en forma meditativa y detenida, al trabajo de modulación expositiva.

\section{La reflexión heterodoxa de las fuentes}

Me ocuparé ahora del tópico de la explicitación de las fuentes mentoras. Con ellas se ha contraído una deuda intelectual, moral y empírica. Por lo tanto, a la par de explicitarlas, sería deseable emprender una breve etnografía de las mismas, no solo para dotar a la investigación de robustez, desenvoltura y consistencia o con el fin de apegarse a un principio de trasparencia intelectual. Así mismo, se buscaría construir "la cita como paisaje", según el aforismo de Humberto Giannini, o bien, "la cita para situarnos, no para definir" (Meschonnic 2007:11). La obra decerteana se impone como ejemplo de la relación investigativa con lo ya pensado; con las referencias y glosa de las fuentes precedentes. Las recurrencias a Kant, Marx, Freud, Wittgenstein y Lefebvre -sin omitir las obras de Michel Foucault y Pierre Bourdieu, con las que emprende una conversación permanente-, trazan el paisaje interpretativo e imaginario de la investigación decerteana.

El hallazgo magistral de Michel de Certeau consistió en captar lo fundamental de dichas obras, constitutivas de un legado, para realzarlo en los intersticios de su reflexión práctica. La obra de Freud constituyó una fuente vital de la antropología decerteana; en particular los análisis contenidos en la obra El malestar de la cultura. El centro del descubrimiento freudiano, que de Certeau rescata, es el ya mencionado tópico psico-cultural del "retorno de lo rechazado" (de Certeau 1996:7). Idea que coincide, ciertamente, con el principio del inconsciente y "lo no escrito" como fundamentos de toda cultura, en la antecesora concepción antropológica de Claude Lévi- Strauss.

Como se ha señalado, el pensamiento decerteano se alimentó de los conceptos capitales de Wittgenstein; particularmente del interés filosófico por el lenguaje ordinario y, en concomitancia, de la orientación ética de su epistemología. Wittgenstein había proporcionado "un plano filosófico a una ciencia contemporánea de lo ordinario" (Giard 1996:xxxiii). En el Tractatus lógico-philosophicus y en Philosophical investigations de Certeau descubrió el análisis del lenguaje "de cada día" y sus maneras diversas de uso cotidiano, gobernadas por reglas pragmáticas que dependen de "formas de vida" (de Certeau 1996:16). 


\section{Reflexiones finales. El proceso de "emancipación personal" del erudito}

Michel de Certeau mantuvo la certeza de que "nadie puede sustraerse de la esfera pública, ni eludir su parte de responsabilidad en lo que es el combate de todos" (de Certeau 1995a:15). Su "pregunta indiscreta", según Giard, el problema más acucioso y éticamente relevante de su pensamiento, fue el "cómo crearse" del sujeto (Giard 1996:XVII). La auto interrogación constituye, posiblemente, la característica más pujante y crítica de la filosofía política decerteana. Como lo explicó Giard, la pregunta filosófica autopoiética sobre cómo crearse resumirá el cambio total de la visión que marca La invención de lo cotidiano. Lo hace al desplazar el interés investigativo hacia la creación anónima, guiada por la maestría intuitiva de los sujetos comunes.

Michel de Certeau estaba convencido de la necesidad de realizar un "duro trabajo de emancipación", que cada sujeto debe llevar a cabo "en sí mismo, por cuenta propia, en la soledad" (de Certeau 1995a:15). Ello, con la finalidad de ser capaz de "tomar responsabilidad en la edificación del cuerpo social" (de Certeau 1995a:15). Es preciso "sacar a la luz la exigencia ética" que gobernará la vida de este sujeto "en el orden de lo visible y lo invisible" (de Certeau 1995a:15). Tal auto exigencia, que implica el ejercicio de una soledad introspectiva, atraviesa sesgadamente el conjunto de la obra decerteana. El proceso de "emancipación personal", enfatizado por Michel de Certeau, resulta indisociable del compromiso ético que llevará al pensador, indefectiblemente, a una "dolorosa fase de desgarramiento, de alejamiento de certezas previas; a veces de ruptura sin retorno" (de Certeau 1995a:15).

Se ha intentado enlazar, en este análisis, tres herramientas inherentes al método antropológico: la observación cualitativa, la aforística "aprehensión poética del objeto" y la autorreflexión de la praxis por parte del investigador plural. En resumidas cuentas, la prefiguración de "otra espacialidad", que daría paso a una "experiencia antropológica, poética y mítica del espacio" (de Certeau 1996:105). Declaración intuitiva que parece condensar el carácter poético de la antropología decerteana: una poética plural que favorezca la producción abierta y antidogmática de la teoría antropológica.

\section{Agradecimientos}

Este artículo retribuye el valioso patrocinio del Programa de Apoyo a Proyectos de Investigación e Innovación Tecnológica (PAPIIT IN403417) "Prácticas cotidianas y emancipación en la lengua" (Rossana Cassigoli responsable académica), adscrito al Centro de Estudios Latinoamericanos de la Facultad de Ciencias Políticas y Sociales de la Universidad Nacional Autónoma de México.

\section{Bibliografía}

Arendt, H. 2005. La condición humana. Barcelona: Paidós.

Badiou, A. 1990. Manifiesto por la filosofía. Madrid: Cátedra.

Badiou, A. 2005. El siglo. Buenos Aires: Manantial.

Benveniste, É. 1971. Problemas de lingüística general. México: Siglo XXI.

De Certeau, M. 1993. La escritura de la historia. México: Universidad Iberoamericana.

De Certeau, M. 1995a. La toma de la palabra y otros escritos políticos. México: Universidad Iberoamericana. 
De Certeau, M. 1995b. Historia y psicoanálisis. México: Universidad Iberoamericana.

De Certeau, M. 1996. El mito de los orígenes. Revista Historia y Grafía 77: 11-29.

Giannini, H. 1987. La reflexión cotidiana. Hacia una arqueología de la experiencia. Santiago: Editorial Universitaria.

Giannini, H. 2011. Notas acerca de la moralidad de la acción. Revista de Filosofía 67: 167-182.

Giard, L. 1996. Historia de una investigación. En: M. de Certeau, L. Giard y P. Mayol. La Invención de lo Cotidiano 2. Habitar, Cocinar. México: Universidad Iberoamericana.

Kristeva, J. 2006. El genio femenino 1. Hannah Arendt. Buenos Aires: Paidós.

Lévi-Strauss, C. 1964. El pensamiento salvaje. México: Fondo de Cultura Económica.

Lévi-Strauss, C. 1971. Arte, lenguaje y etnología. Entrevistas con George Charbonnier. México: Siglo XXI. Meschonnic, H. 2007. La poética como crítica del sentido. Buenos Aires: Mármol Izquierdo.

Recibido el 20 Mar 2018

Aceptado el 15 Jun 2018 